\title{
Clinicopathological Characteristics and Prognosis of Breast Cancer in Young Women - A Single Center Study in a Developing Country
}

This article was published in the following Dove Press journal: Cancer Management and Research

\section{Xiaoliang Sun \\ Jun Liu \\ Haoyang Ji \\ Meng Yang \\ Yao Lu (D)}

Department of General Surgery, ChinaJapan Friendship Hospital, Beijing,

People's Republic of China
Correspondence: Yao Lu

Department of General Surgery, ChinaJapan Friendship Hospital, No. 2 Yinghua East Road, Chaoyang District, Beijing, 100029, People's Republic of China Email zrluyao@163.com
Objective: Breast cancer (BC) in young women tends to be more aggressive. This study highlights the clinicopathological features and outcomes of young breast cancer (YBC) patients in a developing country.

Methods: Consecutive patients aged 35 years or younger with a pathologically confirmed diagnosis of breast cancer treated and followed up at our department were included. Medical records and follow-up databases were reviewed and documented.

Results: The rate of breast conservation and reconstruction surgery is higher in YBC patients. YBC patients are more likely to have tumors over $5 \mathrm{~cm}$, high-grade, hormone receptor negative, triple negative and stage III than old patients. There was no statistically significant difference in the pathological type, lymph node metastasis, and HER2 status. The median follow-up time was 96 months. The disease-free survival (DFS) was significantly worse in the YBC group. However, the overall survival (OS) had no difference between the two groups.

Conclusion: YBC patients had more aggressive pathological features, such as hormone receptor negative, triple negative, high-grade and advanced stage, and poorer DFS than the old counterparts.

Keywords: young age, breast cancer, clinicopathological characteristics, survival, molecular subtypes

\section{Introduction}

Breast cancer $(\mathrm{BC})$ is the most common cancer in females and the second leading cause of cancer-related death in the United States. ${ }^{1}$ BC is typically diagnosed in females older than 60 years and rather rare in women younger than 35 years. $^{2}$ A constant increase in BC diagnoses in women younger than 40 years has been recently reported in several countries, ${ }^{3,4}$ with approximately $11 \%$ of new cases diagnosed in women who are 45 years of age or younger. ${ }^{5}$ The definition of "young women" in the field of breast oncology is not standardized, but most of the literature refers to women aged $\leq 40$ years in developed countries.

$\mathrm{BC}$ is also the highest incidence malignant tumor in Chinese women, but the age of onset is nearly 10 years earlier than that of European and American countries, and the average age of onset is 48.7 years. $^{6}$ Therefore, in China, young breast cancer (YBC) specifically refers to breast cancer patients whose age of onset is $\leq 35$ years old. YBC patients account for more than $10 \%$ of all breast cancer patients, 
and very YBC patients with an age of onset $\leq 25$ years old account for about $0.5 \%$ in our society. ${ }^{7,8}$

In a recent analysis based on the Surveillance, Epidemiology, and End Results (SEER) database from 2004 to 2008, YBC patients had significantly inferior overall and breast-cancer-specific survival than their older counterparts. ${ }^{9}$ There are several possible explanations, such as higher histological grade, lower or absent expression of estrogen receptors (ER) and/or progesterone receptors (PR), higher proportion of triple-negative and Human Epidermal Growth Factor Receptor 2 (HER2) over-expression, and higher lymphovascular invasion for the YBC patients. ${ }^{10,11}$ Conversely, some other reports showed no differences between young and old patients in clinical and histopathological features, such as tumor staging, histological grade, nodal status, ER status, and the molecular subtype of breast cancer. ${ }^{12}$ At present, most of the research related to this is done in developed countries, and there are few relevant data from developing countries. The purpose of this research is to study the clinicopathological characteristics and prognosis of YBC patients from a single center in a developing country.

\section{Materials and Methods}

\section{Inclusion and Exclusion Criteria}

Consecutive patients aged 35 years or younger with a pathologically confirmed diagnosis of breast cancer treated at our department between January 2010 and December 2013 were included. To ensure adequate followup time, we only included patients diagnosed till 2013. Women with previous history of breast cancer, stage IV and unresectable breast cancer or bilateral breast cancer were excluded.

A total of 880 breast cancer patients were treated in our institute from January 2010 to December 2013. Among them, 58 YBC patients have complete medical records and follow-up data with a mean age of 31.5 years. The mean age of breast cancer women in our department was 49.5 years in that 3 years and most patients aged $46 \sim 55$ years. Hence, we randomly selected the same number of patients from the age of $46 \sim 55$ years as our control group. The principle of our random selection is: patients aged $46 \sim 55$ years old with complete medical records and follow-up data, who were operated by the same surgeon and the surgery date is closest to the young breast cancer patients.
Medical records and hospital databases were reviewed and documented.

This study was approved by the ethics board of ChinaJapan Friendship Hospital. Data collection and review of medical records were performed in accordance with the ethical standards of the board and the 1964 Declaration of Helsinki and its later amendments. Because of the retrospective nature of our study and lack of patient identification, informed consent was waived for all participants involved in this study.

\section{Diagnosis and Treatment}

All patients underwent breast ultrasound and mammography examination before operation. The choice of surgery was determined by the consulting surgeon and the patient a modified radical mastectomy with or without reconstruction and breast-conserving surgery (BCS). All patients were given regular adjuvant treatment according to the patient's surgical method, postoperative pathology and molecular subtype.

\section{Staging and Molecular Subtypes}

Staging was assessed according to the American Joint Committee on cancer criteria (8th edition). The ER and $\mathrm{PR}$ results were screened and interpreted as positive when more than $1 \%$ of tumor cells showed positive nuclear staining. HER2 status was reported according to the American Society of Clinical Oncology guidelines. To assign molecular subtypes, we used surrogate definitions based on immunohistochemistry (ER, PR, HER2, and $\mathrm{Ki}$ 67). The triple negative group was defined as ER, PR, and HER2 negative; whereas the HER2 over-expression group comprised ER and PR negative tumors with a positive HER2 receptor status. $\mathrm{Ki} 67$ values were used to segregate Luminal A patients from Luminal B. Luminal A was defined as ER and PR positive, HER2 negative with a low Ki 67 value $(<20 \%)$. Luminal B patients were defined as ER and PR positive and HER2 negative with a high Ki 67 value $(>20 \%)$ or ER positive and HER2 positive with any PR and Ki 67 value. For analysis, Luminal A and $\mathrm{B}$ were combined into a single group (Hormone receptor positive).

\section{Statistical Analysis}

The statistical analysis was performed using SPSS 23.0 version (SPSS Inc., Chicago, IL, USA). Data were summarized as median (range) for continuous variables, and 
number (percentage) for categorical variables. Continuous data with normal distribution were presented as means \pm $\mathrm{SD}$. The non-normally distributed continuous variables were presented as median and interquartile range (IQR). Chi-square test was used to compare categorical variables. Information about the survival status and recurrence was captured from the electronic medical records and the telephone follow-up. Overall survival (OS) was calculated from the date of diagnosis to the date of death from any causes. Disease-free survival (DFS) was calculated from the date of diagnosis to the date of locoregional recurrence, distant metastasis or death due to breast and nonbreast causes. Survival curves were plotted by using the Kaplan-Meier curves. A p-value of $<0.05$ was considered statistically significant.

\section{Results}

From 1st January 2010 to 31st December 2013, 880 female breast cancer patients were treated at our institute with a mean age of 49.5 years old. The YBC group is defined as women at or younger than the age of 35 years at diagnosis. The number of patients in each group is shown in Table 1. A total of 63 patients (7.2\%) were enrolled in the YBC group. Among them, 5 cases were excluded due to incomplete medical data and fail to follow up. Fiftyeight YBC patients who had complete medical records and follow-up data with a mean age of 31.5 years were enrolled in our study. The median follow-up time was 96 months.

\section{Diagnosis and Surgery Results}

The diagnostic sensitivity of breast ultrasound in the control group is higher than the YBC group, and there was statistically significant difference between the two groups (100\% in the control group and $86.2 \%$ in YBC group, $\mathrm{p}=$ $0.003)$. Mammography had a lower sensitivity than ultrasound for both groups in our study, but there was also statistically significant difference between the two groups (79.3\% in the control group and $51.7 \%$ in $\mathrm{YBC}$ group, $\mathrm{p}=$ $0.002)$.

Table I The Numbers of Patients in Each Age Group

\begin{tabular}{|l|l|l|l|l|l|}
\hline Age (Years) & $\leq 35$ & $\mathbf{3 6} 45$ & $\mathbf{4 6}$ 55 & $\mathbf{5 6} \mathbf{6 5}$ & $>\mathbf{6 5}$ \\
\hline No. & 63 & 145 & 307 & 206 & 159 \\
\hline
\end{tabular}

Table 2 Patients' Operative Method

\begin{tabular}{|c|c|c|c|}
\hline \multirow{2}{*}{$\begin{array}{l}\text { Operative } \\
\text { Method }\end{array}$} & \multicolumn{2}{|c|}{ Group } & \multirow[t]{2}{*}{$P$ value* } \\
\hline & $\begin{array}{c}\text { Younger } \\
\text { Group }(n=58)\end{array}$ & $\begin{array}{l}\text { Older Group } \\
\qquad(n=58)\end{array}$ & \\
\hline $\begin{array}{l}\text { Modified radical } \\
\text { mastectomy } \\
\text { without } \\
\text { reconstruction }\end{array}$ & $34 / 58=58.6 \%$ & $48 / 58=82.8 \%$ & 0.004 \\
\hline $\begin{array}{l}\text { Breast-conserving } \\
\text { surgery }(B C S)\end{array}$ & $16 / 58=27.6 \%$ & $10 / 58=17.2 \%$ & 0.182 \\
\hline $\begin{array}{l}\text { Modified radical } \\
\text { mastectomy with } \\
\text { reconstruction }\end{array}$ & $8 / 58=13.8 \%$ & 0 & 0.003 \\
\hline $\begin{array}{l}\mathrm{BCS} \text { and breast } \\
\text { reconstruction }\end{array}$ & $24 / 58=41.4 \%$ & $10 / 58=17.2 \%$ & 0.004 \\
\hline
\end{tabular}

Notes: Chi-square test was used to compare categorical variables. $* P$ value $<0.05$ was considered statistically significant.

Elderly patients are more inclined to choose modified radical surgery without reconstruction $(82.8 \%$ vs. $58.6 \%$, $\mathrm{p}=0.004)$. More YBC patients choose BCS, but the difference between the two groups was not statistically significant. None of the older patients choose reconstruction surgery after modified radical mastectomy. There were more patients in the YBC group opted for BCS and modified radical mastectomy with reconstruction as compared with their older counterparts $(41.4 \%$ vs. $17.2 \%, \mathrm{p}=0.004)$. The operative method of the two groups is summarized in Table 2.

\section{Pathological Characteristics}

There are some similar pathological characteristics between the two groups, such as the histology (invasive carcinoma or carcinoma in situ) and lymph node metastasis. A greater proportion of the YBC patients presented with stage III disease than the older patients $(24.2 \%$ vs. $10.3 \%, \mathrm{p}=0.049$ ). There were $13.8 \%$ patients' tumor size over $5 \mathrm{~cm}$ in the $\mathrm{YBC}$ group and none in the control group $(\mathrm{p}=0.003)$. There was a significantly higher incidence of high-grade (GIII) tumors in the YBC group $(65.5 \%$ vs. $31 \%, p=0.000)$. The incidence of hormone receptor negative tumors $(55.2 \%$ vs. $34.5 \%, \mathrm{p}=0.025)$ and triple negative tumors $(31.1 \%$ vs. $13.8 \%, \mathrm{p}=0.026)$ were significantly higher in the YBC group, whereas the HER2 positive tumors were similarly distributed between the two groups $(24.1 \%$ vs. $20.7 \%, p=0.656)$. The 
Table 3 Patients' Clinicopathological Characteristics

\begin{tabular}{|c|c|c|c|}
\hline \multirow[t]{2}{*}{ Clinicopathological Characteristics } & \multicolumn{2}{|c|}{ Group } & \multirow[t]{3}{*}{$P$ value* } \\
\hline & Younger Group $(n=58)$ & Older Group $(n=58)$ & \\
\hline Mean Age (y) & $31.5 \pm 3.3$ & $56.5 \pm 2.8$ & \\
\hline $\begin{array}{l}\text { Histology } \\
\text { Invasive carcinoma } \\
\text { Carcinoma in situ }\end{array}$ & $\begin{array}{c}54 / 58=93.1 \% \\
4 / 58=6.9 \%\end{array}$ & $\begin{array}{c}52 / 58=89.7 \% \\
6 / 58=10.3 \%\end{array}$ & 0.508 \\
\hline \multicolumn{4}{|l|}{ Tumor size } \\
\hline $\begin{array}{l}\leq 2 \mathrm{~cm} \\
2-5 \mathrm{~cm} \\
>5 \mathrm{~cm}\end{array}$ & $\begin{array}{c}24 / 58=41.4 \% \\
26 / 58=44.8 \% \\
8 / 58=13.8 \%\end{array}$ & $\begin{array}{c}18 / 58=31 \% \\
40 / 58=69 \% \\
0\end{array}$ & $\begin{array}{l}0.246 \\
0.009 \\
0.003\end{array}$ \\
\hline $\begin{array}{l}\text { Grade } \\
\text { High (GIII) } \\
\text { Moderate and low (GI \& II) } \\
\text { Lymph node metastasis } \\
\text { Positive } \\
\text { Negative }\end{array}$ & $\begin{array}{l}38 / 58=65.5 \% \\
20 / 58=34.5 \% \\
32 / 58=55.2 \% \\
26 / 58=44.8 \%\end{array}$ & $\begin{array}{l}18 / 58=31 \% \\
40 / 58=69 \% \\
30 / 58=51.7 \% \\
28 / 58=48.3 \%\end{array}$ & $\begin{array}{l}0.000 \\
0.092\end{array}$ \\
\hline \multicolumn{4}{|l|}{ Pathologic stage } \\
\hline $\begin{array}{l}0 \\
1 \\
2 \\
3\end{array}$ & $\begin{array}{c}4 / 58=6.9 \% \\
2 / 58=3.4 \% \\
38 / 58=65.5 \% \\
\mid 4 / 58=24.2 \%\end{array}$ & $\begin{array}{c}6 / 58=10.3 \% \\
8 / 58=13.9 \% \\
38 / 58=65.5 \% \\
6 / 58=10.3 \%\end{array}$ & $\begin{array}{c}0.508 \\
0.047 \\
1 \\
0.049\end{array}$ \\
\hline \multicolumn{4}{|l|}{ Molecular subtypes } \\
\hline $\begin{array}{l}\text { Hormone receptor negative } \\
\text { HER2 over-expression } \\
\text { Triple negative }\end{array}$ & $\begin{array}{l}32 / 58=55.2 \% \\
14 / 58=24.1 \% \\
18 / 58=31.1 \%\end{array}$ & $\begin{array}{l}20 / 58=34.5 \% \\
12 / 58=20.7 \% \\
8 / 58=13.8 \%\end{array}$ & $\begin{array}{l}0.025 \\
0.656 \\
0.026\end{array}$ \\
\hline
\end{tabular}

Notes: Continuous data with normal distribution were presented as means $\pm \mathrm{SD}$. Chi-square test was used to compare categorical variables. $* P$ value $<0.05$ was considered statistically significant.

clinicopathological details of the two groups are summarized in Table 3.

\section{Prognosis}

The DFS was significantly worse in the YBC group ( $75.9 \%$ vs. $96.6 \%, \mathrm{p}=0.001)$. However, there was no difference in the OS (93.1\% vs. 96.6\%, p = 0.404) (Figures 1 and 2, respectively).

\section{Discussion}

$\mathrm{BC}$ is the most common solid malignant tumors in women and the second leading cause of cancer-related death both in the United States and China. Most BC is diagnosed in women older than 60 years and rather rare in young women. BC patients younger than 40 years old account for less than $7 \%$ of all $\mathrm{BC}$ patients in developed countries. ${ }^{13} \mathrm{BC}$ is associated with peculiar features in developing countries, such as median age at diagnosis is at least 10 years younger than that of developed countries. Although YBC patients compose a small proportion of all breast cancer diagnoses, these patients have been shown to have poor prognosis than older patients. ${ }^{14-16} \mathrm{BC}$ is also the leading cause of cancer-related death among females younger than 35 years old. ${ }^{17,18}$

A total of 880 female breast cancer patients were treated in our institute between 2010 and 2013 among which $63(7.2 \%)$ were YBC patients. The incidence of YBC from our research seems lower than some other studies due to our inclusion criteria which excluded women with previous history of breast cancer, stage IV and unresectable breast cancer or bilateral breast cancer. Another developing country's study showed $15 \%$ of YBC had stage IV disease at diagnosis. ${ }^{19}$ A clinical study in China showed that most young breast cancer patients had a family history of breast or ovarian cancer $(8.8 \%)$, and 


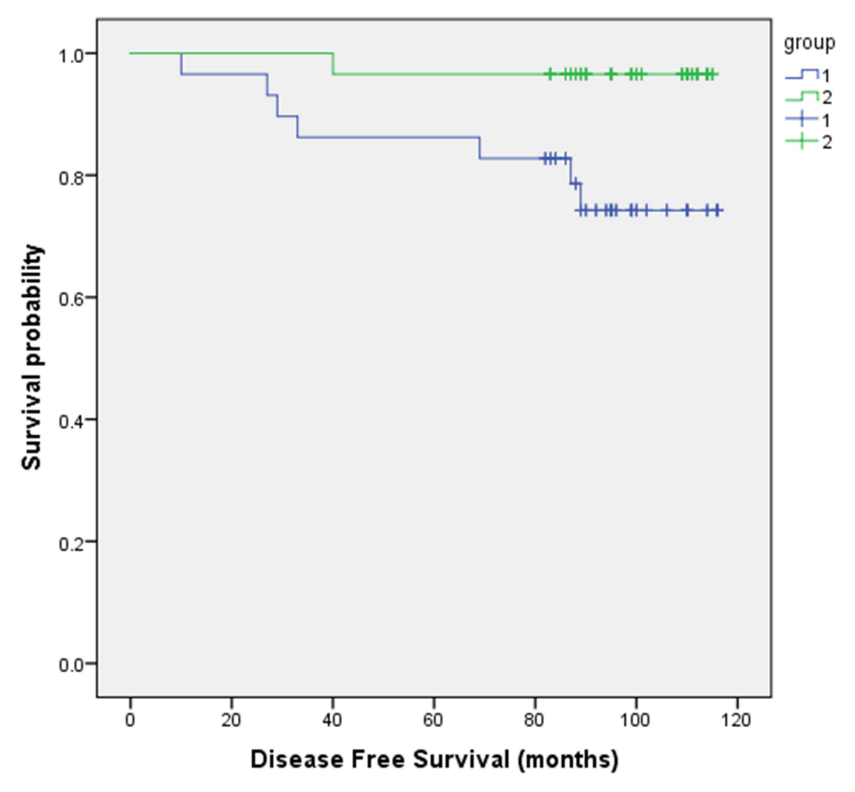

Figure I The DFS of the two groups.

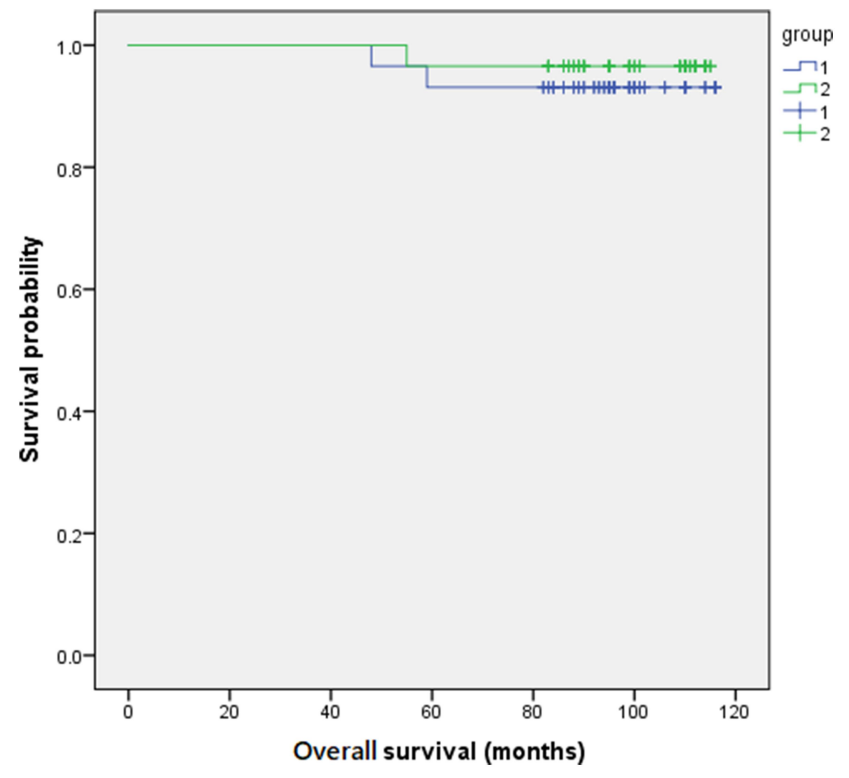

Figure 2 The OS of the two groups.

$30.8 \%$ were stage III or IV disease. ${ }^{20}$ Therefore, with the addition of stage IV YBC patients, the incidence is similar to those reported literature.

The sensitivity of mammography is very low in young women with dense breasts, so the ultrasound is the firstchoice imaging tool for the young females, which is associated with higher sensitivity and no risks related to ionizing radiation exposure. $^{21-23}$ In our study, the sensitivity of ultrasound and mammography for the young women is $86.2 \%$ and $51.7 \%$, respectively $(\mathrm{p}=0.000)$.

BCS and breast reconstruction can enhance patients' body image and improve quality of life, especially in the young patients. A meta-analyse reported a high risk of local recurrence in younger women versus older women undergoing BCS. ${ }^{24}$ Matthews reported that YBC women had a higher local recurrence rate than older women after $\mathrm{BCS}$ and radiation, but the OS was higher for BCS compared with mastectomy. ${ }^{25}$ In our study, 16 (27.6\%) YBC patients chose BCS which was higher than the control group (17.2\%), but there was no statistically significant difference between the two groups $(\mathrm{p}=0.182$ ). Old patients are more likely to choose modified radical surgery without reconstruction $(82.8 \% \%$ vs. $58.6 \%, \mathrm{p}=0.004)$. Only 8 patients chose breast reconstruction in all patients. The rate of breast reconstruction in our department is lower than the developed countries. While cultural differences do exist but financial coverage could have been an important reason for this because breast reconstruction is expensive and not covered by insurance in China.

From our research, we found some special clinical and pathological features which imply poor prognosis in the YBC patients. The immunohistochemistry revealed a higher incidence of hormone negative tumors in the YBC group (55.2\% vs. $34.5 \%, \mathrm{p}=0.025)$ which is in accordance with reports published from another developing country, India, ranging from $48.8 \%$ to $52.4 \%{ }^{26-29}$ Another study from a developed country observed only $33.7 \%$ tumors were ER negative in women younger than 40 years. ${ }^{30}$ So there might be a wide variation in the proportion of hormone negative tumors across different geographies. YBC women were found to have more advanced disease, and more likely to be diagnosed with high-grade (GIII) and triple negative breast cancer than older women in the present study. Triple negative breast cancer has been associated with a higher risk of recurrence and metastasis. ${ }^{31}$ Keegan's study reported that YBC patients are more likely to have a diagnosis of higherstage disease. ${ }^{15}$ In our study, the YBC patients were significantly more likely to present with stage III disease than the older patients $(24.2 \%$ vs $10.3 \%, \mathrm{p}=0.049)$. This is another reason why YBC patients have a poor prognosis. $65.5 \%$ and $55.2 \%$ of YBC women were diagnosed with high-grade (GIII) and triple negative breast cancer which were significantly higher than the control group in our study, consistent with other previous findings. ${ }^{32-34}$ 
In our study, we found no significant difference of the HER2 over-expression between the two groups (24.1\% vs. $20.7 \%, p=0.656$ ). A Sweden study showed that the HER2 positive tumors accounted for $20.4 \%$ in young women versus $8.2 \%$ in the older age group. ${ }^{35}$

From our study, the DFS was significantly lower in the YBC group $(75.9 \%$ vs. $96.6 \%, p=0.001)$, however, the OS did not show a statistically significant difference between the two groups $(93.1 \%$ vs. $96.6 \%, p=0.696)$, but it did demonstrate a trend toward decreased survival in YBC women which is consistent with Hwang's study. ${ }^{36}$ This could be caused by the long survival time of breast cancer even if recrudescence or metastasizes.

This study has several limitations, such as its retrospective feature and its potential for referral bias to a single centre. Additionally, this study excluded patients with stage IV and unresectable $\mathrm{BC}$, so the results can only represent YBC patients with an early stage who admitted to the surgery department for operation. Finally, the limited number may have affected the statistical power. We plan to add more patients especially YBC patients and continue to follow up with these patients. We hope to have more credible results with the accumulation of more mature data in the future.

According to our study, mammography had a lower sensitivity than ultrasound for the YBC women. Much more $\mathrm{YBC}$ patients opted for breast-conserving and breast reconstruction surgery The YBC patients had peculiar pathological characteristics, such as more high-grade (GIII) tumors, hormone receptor negative tumors, triple negative tumors and higher-stage tumors. This may explain that is why the YBC patients had a worse DFS as compared with their older counterparts. Clinical trials designed specifically to focus on YBC is urgently needed. Further research aimed at developing new treatment schedules for the YBC patients may improve their prognosis.

\section{Funding}

This research received no specific grant from any funding agency in the public, commercial, or not-for-profit sectors.

\section{Disclosure}

The authors declare that there is no conflict of interest.

\section{References}

1. Siegel RL, Miller KD, Jemal A. Cancer statistics, 2020. CA Cancer J Clin. 2020;70(1):7-30. doi:10.3322/caac.21590
2. Cancer Stat Facts. Female breast cancer. 2018. Available from: https:// seer.cancer.gov/statfacts/html/breast.html. Accessed February 4, 2018.

3. Ferlay J, Soerjomataram I, Ervik M, et al. GLOBOCAN 2012 v1.0, cancer incidence and mortality worldwide: IARC cancer-base no. 11, 2013 [Lyon, France: international agency for research oncancer]. Available from: http://globocan.iarc.fr/. Accessed February 3, 2021.

4. Villarreal-Garza C, Aguila C, Magallanes-Hoyos MC, et al. Breast cancer in young women in Latin America: an unmet, growing burden. Oncologist. 2013;18(12):1298-1306. doi:10.1634/theoncologist.20130321

5. National Cancer Institute. Surveillance, epidemiology and end results program. Available from: http://seer.cancer.gov/statfacts/html/breast. html. Accessed May 7, 2017.

6. Chen W, Zheng R, Baade PD, et al. Cancer statistics in China, 2015. CA Cancer J Clin. 2016;66(2):115-132. doi:10.3322/caac.21338

7. Li J, Zhang BN, Fan JH, et al. A nation-wide multicenter 10-year (1999-2008) retrospective clinical epidemiological study of female breast cancer in China. BMC Cancer. 2011;11:364. doi:10.1186/ 1471-2407-11-364

8. Yao S, Xu B, Ma F, et al. Breast cancer in women younger than 25: clinicopathological features and prognostic factors. Ann Oncol. 2009;20(2):387-389. doi:10.1093/annonc/mdn711

9. Chen H-L, Zhou M-Q, Tian W, et al. Effect of age on breast cancer patient prognoses: a population-based study using the SEER 18 database. PLoS One. 2016;11(10):e0165409. doi:10.1371/journal. pone. 0165409

10. Azim HA Jr, Partridge AH. Biology of breast cancer in young women. Breast Cancer Res. 2014;16(4):427. doi:10.1186/s13058014-0427-5

11. Lambertini M, Pinto AC, Ameye L, et al. The prognostic performance of adjuvant! Online and Nottingham prognostic index in young breast cancer patients. $B r \quad J$ Cancer. 2016;115 (12):1471-1478. doi:10.1038/bjc.2016.359

12. Anders CK, Fan C, Parker JS, et al. Breast carcinomas arising at a young age: unique biology or a surrogate for aggressive intrinsic subtypes? J Clin Oncol. 2011;29(1):e18-e20. doi:10.1200/ JCO.2010.28.9199

13. DeSantis C, Ma J, Bryan L, Jemal A. Breast cancer statistics, 2013. CA Cancer J Clin. 2014;64:52-62. doi:10.3322/caac.21203

14. $\mathrm{Fu} \mathrm{J}, \mathrm{Wu} \mathrm{L}, \mathrm{Fu} \mathrm{W}$, et al. How young is too young in breast cancer?-Young breast cancer is not a unique biological subtype. Clin Breast Cancer. 2018;18(1):e25-e39. doi:10.1016/j.clbc.2017.05.015

15. Keegan TH, DeRouen MC, Press DJ, et al. Occurrence of breast cancer subtypes in adolescent and young adult women. Breast Cancer Res. 2012;14(2):R55. doi:10.1186/bcr3156

16. O'Brien KM, Sun J, Sandler DP, DeRoo LA, Weinberg CR. Risk factors for young-onset invasive and in situ breast cancer. Cancer Causes Control. 2015;26(12):1771-1778. doi:10.1007/s10552-015-0670-9

17. Freedman RA, Partridge AH. Management of breast cancer in very young women. Breast. 2013;22(Suppl 2):S176-S179. doi:10.1016/j. breast.2013.07.034

18. Rosenberg SM, Partridge AH. Management of breast cancer in very young women. Breast. 2015;24(Suppl 2):S154-S158. doi:10.1016/j. breast.2015.07.036

19. Abdel-Razeq H, Almasri H, Abdel Rahman F, et al. Clinicopathological characteristics and treatment outcomes of breast cancer among adolescents and young adults in a developing country. Cancer Manag Res. 2019;11:9891-9897. doi:10.2147/CMAR.S229337

20. Li L, Yi Z, Li C, et al. Integrative clinical genomics of early-onset breast cancer. J Clin Oncol. 2018;36(15_suppl):1541. doi:10.1200/ JCO.2018.36.15_suppl.1541

21. Mandelson MT, Oestreicher N, Porter PL, et al. Breast density as a predictor of mammographic detection: comparison of interval- and screen-detected cancers. J Natl Cancer Inst. 2000;92(13):1081-1087. doi:10.1093/jnci/92.13.1081 
22. Foxcroft LM, Evans EB, Porter AJ. The diagnosis of breast cancer in women younger than 40. Breast. 2004;13(4):297-306. doi:10.1016/j. breast.2004.02.012

23. Evans A, Trimboli RM, Athanasiou A, et al. Breast ultrasound: recommendations for information to women and referring physicians by the European Society of Breast Imaging. Insights Imaging. 2018;9 (4):449-461. doi:10.1007/s13244-018-0636-z

24. He XM, Zou DH. The association of young age with local recurrence in women with early-stage breast cancer after breast-conserving therapy: a meta-analysis. Sci Rep. 2017;7(1):11058. doi:10.1038/ s41598-017-10729-9

25. Matthews RH, McNeese MD, Montague ED, et al. Prognostic implications of age in breast cancer patients treated with tumorectomy and irradiation or with mastectomy. Int $J$ Radiat Oncol Biol Phys. 1988;14(4):659-663. doi:10.1016/0360-3016(88)90086-7

26. Kumar RV, Panwar D, Amirtham U, et al. Estrogen receptor, progesterone receptor, and human epidermal growth factor receptor-2 status in breast cancer: a retrospective study of 5436 women from a regional cancer center in South India. South Asian J Cancer. 2018;7(1):7-10. doi:10.4103/sajc.sajc_211_17

27. Patnayak R, Jena A, Rukmangadha N, et al. Hormone receptor status (estrogen receptor, progesterone receptor), human epidermal growth factor-2 and p53 in South Indian breast cancer patients: a tertiary care center experience. Indian $J$ Med Paediatr Oncol. 2015;36 (2):117-122. doi:10.4103/0971-5851.158844

28. Manjunath S, Prabhu JS, Kaluve R, et al. Estrogen receptor negative breast cancer in India: do we really have higher burden of this subtype? Indian J Surg Oncol. 2011;2(2):122-125. doi:10.1007/ s13193-011-0072-8

29. Ghosh J, Gupta S, Desai S, et al. Estrogen, progesterone and HER2 receptor expression in breast tumors of patients, and their usage of HER2-targeted therapy, in a tertiary care centre in India. Indian $J$ Cancer. 2011;48(4):391-396. doi:10.4103/0019-509X.92245
30. Copson E, Eccles B, Maishman T, et al. Prospective observational study of breast cancer treatment outcomes for UK women aged 18-40 years at diagnosis: the POSH study. J Natl Cancer Inst. 2013;105(13):978-988. doi:10.1093/jnci/djt134

31. Voduc KD, Cheang MCU, Tyldesley S, et al. Breast cancer subtypes and the risk of local and regional relapse. J Clin Oncol. 2010;28 (10):1684-1691. doi:10.1200/JCO.2009.24.9284

32. Passhak M, Shachar SS, Bar-Sela G, et al. Breast cancer in young women aged 35 and under: patterns of care and outcome. Breast J. 2018;24(3):441-443. doi:10.1111/tbj.12966

33. Greally M, Kielty J, Watson GA, et al. Where youth matters clinicopathologic characteristics and emerging trends in treatment and outcomes in young Irish women with breast cancer. Ir $\mathrm{J} \mathrm{Med}$ Sci. 2019;188(1):59-67. doi:10.1007/s11845-018-1832-z

34. de Azambuja E, Holmes AP, Piccart-Gebhart M, et al. Lapatinib with trastuzumab for HER2-positive early breast cancer (NeoALTTO): survival outcomes of a randomised, open-label, multicentre, Phase 3 trial and their association with pathological complete response. Lancet Oncol. 2014;15(10):1137-1146. doi:10.1016/S1470-2045(14) 70320-1

35. Fredholm H, Magnusson K, Lindström LS, et al. Long-term outcome in young women with breast cancer: a population-based study. Breast Cancer Res Treat. 2016;160(1):131-143. doi:10.1007/s10549-0163983-9

36. Hwang KT, Kim J, Jung J, et al. Impact of breast cancer subtypes on prognosis of women with operable invasive breast cancer: a population-based study using SEER database. Clin Cancer Res. 2019;25(6):1970-1979. doi:10.1158/1078-0432.CCR-18-2782

\section{Publish your work in this journal}

Cancer Management and Research is an international, peer-reviewed open access journal focusing on cancer research and the optimal use of preventative and integrated treatment interventions to achieve improved outcomes, enhanced survival and quality of life for the cancer patient.
The manuscript management system is completely online and includes a very quick and fair peer-review system, which is all easy to use. Visit http://www.dovepress.com/testimonials.php to read real quotes from published authors. 